\title{
ESTIMATED RELATIONS BETWEEN THE MAIN THERMOSPHERIC NEUTRAL COMPONENTS AT IONOSPHERIC F1-LAYER HEIGHTS ABOVE IRKUTSK IN 2014-2017
}

\section{G.P. Kushnarenko}

Institute of Solar-Terrestrial Physics SB RAS,

Irkutsk, Russia, kusch@iszf.irk.ru

\section{O.E. Yakovleva}

Institute of Solar-Terrestrial Physics SB RAS,

Irkutsk, Russia, yakovleva@iszf.irk.ru

\author{
G.M. Kuznetsova \\ Institute of Solar-Terrestrial Physics SB RAS, \\ Irkutsk,Russia,kuz@iszf.irk.ru
}

\begin{abstract}
We have estimated seasonal variations in the main thermospheric gas components $[\mathrm{O}] /\left[\mathrm{N}_{2}\right]$ and $\left[\mathrm{O}_{2}\right] /[\mathrm{O}]$ for the period 2014-2017. We have used the well-known authoring technique and electron density measurements made with the Irkutsk digisonde $\left(52^{\circ} \mathrm{N}\right.$, $\left.104^{\circ} \mathrm{E}\right)$ at ionospheric F1-layer heights under different geomagnetic activity conditions. We have found that at these heights during geomagnetic disturbances in all seasons the molecular component of the neutral composition of the thermosphere increases and the atomic component decreases. In comparison with 2014, $\left[\mathrm{O}_{2}\right] /[\mathrm{O}]$ values increased by 2017 under quiet and dis-
\end{abstract}

turbed geomagnetic conditions: up to $30 \%$ and $20 \%$ in summer and spring respectively; up to $10 \%$ in winter and autumn. The $[\mathrm{O}] /\left[\mathrm{N}_{2}\right]$ ratio decreased by an average of $15 \%$ by 2017 . The assumption has been confirmed that in summer under quiet geomagnetic conditions the relative molecular oxygen content $\left[\mathrm{O}_{2}\right] /[\mathrm{O}]$ increases with decreasing solar activity.

Keywords: geomagnetic disturbances, gas component ratios.

\section{INTRODUCTION}

At heights of the middle ionosphere, where the F1region is located, the main indicator of the state of the thermosphere is the gas composition, which is largely represented by the ratio of the concentration of oxygen atoms to that of oxygen and nitrogen molecules. The electron density $N_{\mathrm{e}}$ and the $N(h)$ profile shape are most affected by the gas composition of the thermosphere at heights below $200 \mathrm{~km}$, where the photochemical equilibrium condition is usually well fulfilled. With a semi-empirical model (SEM) [Shchepkin et al., 1998] it is relatively simple to describe the relationship of $N_{\mathrm{e}}$ with the gas composition of the thermosphere, its temperature, and solar flux. Employing SEM along with regular measurements of the electron density made with the Irkutsk ionosonde $\left(52^{\circ} \mathrm{N}, 104^{\circ} \mathrm{E}\right)$, we can obtain ratios of the main gas components $[\mathrm{O}] /\left[\mathrm{N}_{2}\right]$ and $\left[\mathrm{O}_{2}\right] /[\mathrm{O}]$, using a authoring technique [Shchepkin et al., 2008, 2009], at heights 120-200 km for given conditions. As a follow-up to [Kushnarenko et al., 2014, 2015], we have made calculations for the period 2014-2017, which combines conditions of solar activity maximum and decay. We have studied the seasonal behavior of $[\mathrm{O}] /\left[\mathrm{N}_{2}\right]$ and $\left[\mathrm{O}_{2}\right] /[\mathrm{O}]$ at the said ionospheric heights under quiet and disturbed geomagnetic conditions.

\section{METHOD AND DATA IN USE}

The semi-empirical model (SEM), based on a regression equation [Shchepkin et al., 2009], can be invoked to analyze the current state of the gas composition of the thermosphere:

$$
\begin{aligned}
& N_{\mathrm{e}} / N_{\mathrm{av}}=X_{1}+X_{2}\left[n_{1} /\left(5 n_{2}+n_{3}\right)\right]^{1.5}+ \\
& +X_{3}\left(n_{1} / n_{3}\right)^{0.5}(\cos \chi)^{0.5}+ \\
& \quad+X_{4} \exp \left[-\left(T_{\mathrm{ex}}-600\right) / 600\right]+X_{5}\left(E / E_{0}\right) .
\end{aligned}
$$

Here, $N_{\mathrm{e}}$ is the electron density; $N_{\mathrm{av}}$ is the average $N_{\mathrm{e}}$ for the entire data set separately for each height; $X_{j}$ is the coefficients of the model equation; $n_{1}, n_{2}, n_{3}$ are concentrations of oxygen atoms and oxygen and nitrogen molecules respectively; $\chi$ is the solar zenith angle; $T_{\text {ex }}$ is the exospheric temperature; $E_{0}$ is the energy of ionizing radiation flux $E$ at solar maximum [Tobiska, Eparvier, 1998]. Write Equation (1) as follows:

$$
\begin{aligned}
& N_{\mathrm{e}} / N_{\mathrm{av}}=X_{1}+X_{2} R \sqrt{R} W+X_{3} \sqrt{R}(\cos \chi)^{0.5}+ \\
& +X_{4} \exp \left[-\left(T_{\mathrm{ex}}-600\right) / 600\right]+X_{5}\left(E / E_{0}\right) .
\end{aligned}
$$

where $R=\left([\mathrm{O}] /\left[\mathrm{N}_{2}\right]\right) ; \quad W=\left[1 /\left(1+5 R_{2}\right)\right]^{1.5} ; R_{2}=\left[\mathrm{O}_{2}\right] /\left[\mathrm{N}_{2}\right]$; $R_{2} / R=\left[\mathrm{O}_{2}\right] /[\mathrm{O}] ;[\mathrm{O}],\left[\mathrm{O}_{2}\right]$, and $\left[\mathrm{N}_{2}\right]$ are the concentrations of atomic oxygen and molecular oxygen and nitrogen respectively. In the calculations, we have used thermospheric models [Hedin, 1987; Picone et al., 2002]. The ratios $[\mathrm{O}] /\left[\mathrm{N}_{2}\right]$ and $\left[\mathrm{O}_{2}\right] /[\mathrm{O}]$ were estimated using electron density measurements made with a digisonde during daylight hours at heights of $120,130, \ldots, 190,200 \mathrm{~km}$ in 2014 2017. Using the data from Expression (2), we can evaluate the desired ratios $R, R_{2}, R_{2} / R$.

\section{RESULTS}

The method allows us to estimate $[\mathrm{O}] /\left[\mathrm{N}_{2}\right]$ and $\left[\mathrm{O}_{2}\right] /[\mathrm{O}]$ for daylight hours $(7-18 \mathrm{LT})$, using data on electron density at heights $120-200 \mathrm{~km}$. The calculations have been made for all days with different geo- 
magnetic conditions in all seasons of the period 2014 2017, which includes solar activity maximum (2014) and decline in solar activity (Table 1).

For each quiet and disturbed days, we first calculated the average ratio for the midday hours (10-14 LT), and then found the average ratio separately for quiet and disturbed days of each season in these years. For the latter ratios, we computed the mean square deviation $\sigma$ (see Table 2). Disturbed days were considered those with the geomagnetic index $A_{\mathrm{p}}>10$. The $F 10.7, A_{\mathrm{p}}$, and Dst indices were taken from the WDC-C2 database in Kyoto [http://wdc.kugi.kyoto-u.ac.jp].

\section{THE $\left[\mathrm{O}_{2}\right] /[\mathrm{O}]$ RATIO}

Variations in the average seasonal values of $\left[\mathrm{O}_{2}\right] /[\mathrm{O}]$ under quiet conditions in 2014-2017 are more clearly shown in Figure 1 . The ratio $\left[\mathrm{O}_{2}\right] /[\mathrm{O}]$ at the F1-layer heights in all seasons increases by the end of this period. The highest values of $\left[\mathrm{O}_{2}\right] /[\mathrm{O}]$ are observed in summer: from 2014 to 2017 the ratio increases by $30 \%$.

In summer under quiet geomagnetic conditions, the relative content of molecular oxygen $\left[\mathrm{O}_{2}\right] /[\mathrm{O}]$ is likely to increase with decreasing solar activity. This is confirmed by the results of the study [Kushnarenko et al., 2011] on the station Irkutsk, which recorded an increase in $\left[\mathrm{O}_{2}\right] /[\mathrm{O}]$ during the long solar minimum of 2007-2009.

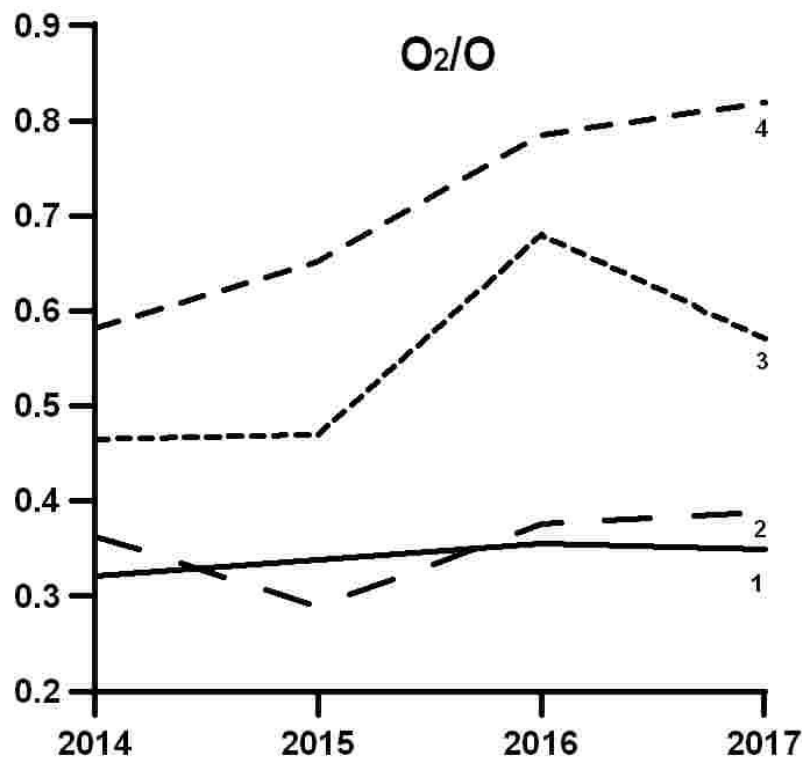

Figure 1. Seasonal variations in $\left[\mathrm{O}_{2}\right] /[\mathrm{O}]$ under quiet geomagnetic conditions: 1 - winter, 2 - fall, 3 - spring, 4 summer. Along the $\mathrm{X}$-axis are years of the period under study

Annual average $F 10.7$ for 2003-2017

Table 1

\begin{tabular}{|c|c|c|c|c|c|c|c|c|c|c|c|c|c|c|c|}
\hline Year & '03 & '04 & '05 & '06 & '07 & '08 & '09 & '10 & ' 11 & '12 & '13 & '14 & '15 & '16 & '17 \\
\hline$F 10.7$ & 128 & 106 & 92 & 80 & 74 & 69 & 71 & 80 & 113 & 120 & 123 & 146 & 118 & 89 & 77 \\
\hline
\end{tabular}

Table 2

Average ratios $[\mathrm{O}] /\left[\mathrm{N}_{2}\right]$ and $\left[\mathrm{O}_{2}\right] /[\mathrm{O}]$ for 2014-2017 (Irkutsk)

\begin{tabular}{|c|c|c|c|c|c|c|c|c|c|}
\hline \multirow{2}{*}{ Year } & \multirow{2}{*}{$F 10.7$} & \multicolumn{9}{|c|}{$[\mathrm{O}] /\left[\mathrm{N}_{2}\right]$} \\
\cline { 3 - 11 } & & \multicolumn{2}{|c|}{ winter } & \multicolumn{2}{c|}{ spring } & \multicolumn{2}{c|}{ summer } & \multicolumn{2}{c|}{ fall } \\
\cline { 3 - 10 } & disturb. & quiet & disturb. & quiet & disturb. & quiet & disturb. & quiet \\
\hline 2014 & 146 & 0.331 & 0.343 & 0.240 & 0.280 & 0.179 & 0.191 & 0.313 & 0.327 \\
\hline$\sigma, 2014$ & & 0.085 & 0.060 & 0.054 & 0.064 & 0.035 & 0.035 & 0.049 & 0.082 \\
\hline 2015 & 118 & 0.276 & 0.414 & 0.216 & 0.229 & 0.164 & 0.171 & 0.218 & 0.244 \\
\hline$\sigma, 2015$ & & 0.059 & 0.074 & 0.051 & 0.057 & 0.030 & 0.028 & 0.062 & 0.078 \\
\hline 2016 & 89 & 0.289 & 0.314 & 0.196 & 0.217 & 0.136 & 0.152 & 0.181 & 0.240 \\
\hline$\sigma, 2016$ & & 0.074 & 0.084 & 0.056 & 0.058 & 0.022 & 0.028 & 0.059 & 0.049 \\
\hline 2017 & 77 & 0.229 & 0.277 & 0.160 & 0.170 & 0.124 & 0.140 & 0.165 & 0.250 \\
\hline$\sigma, 2017$ & & 0.068 & 0.063 & 0.042 & 0.032 & 0.023 & 0.040 & 0.071 & 0.076 \\
\hline & & & & \multicolumn{7}{|c|}{$\left[\mathrm{O}_{2}\right] /[\mathrm{O}]$} & & & \\
\hline 2014 & 146 & 0.345 & 0.321 & 0.559 & 0.465 & 0.706 & 0.592 & 0.401 & 0.363 \\
\hline$\sigma, 2014$ & & 0.134 & 0.109 & 0.160 & 0.147 & 0.222 & 0.191 & 0.071 & 0.059 \\
\hline 2015 & 118 & 0.396 & 0.338 & 0.528 & 0.470 & 0.765 & 0.652 & 0.490 & 0.289 \\
\hline$\sigma, 2015$ & & 0.108 & 0.090 & 0.170 & 0.173 & 0.248 & 0.203 & 0.074 & 0.083 \\
\hline 2016 & 89 & 0.412 & 0.355 & 0.686 & 0.670 & 0.809 & 0.795 & 0.494 & 0.376 \\
\hline$\sigma, 2016$ & & 0.134 & 0.130 & 0.127 & 0.140 & 0.284 & 0.294 & 0.056 & 0.044 \\
\hline 2017 & 77 & 0.468 & 0.349 & 0.712 & 0.571 & 0.860 & 0.819 & 0.520 & 0.389 \\
\hline$\sigma, 2017$ & & 0.189 & 0.160 & 0.156 & 0.204 & 0.297 & 0.335 & 0.195 & 0.203 \\
\hline
\end{tabular}


In other seasons, the initial values of 2014 by 2017 are as follows: in spring the $\left[\mathrm{O}_{2}\right] /[\mathrm{O}]$ ratio increases by $20 \%$; in winter and fall, within $10 \%$. Also noteworthy is the $30 \%$ spring increase in $\left[\mathrm{O}_{2}\right] /[\mathrm{O}]$ during quiet days in 2016. Probably, a reason is the quite significant decrease in solar activity in 2016, as compared to 2015: the annual average $F 10.7$ index changed from 118 to 89 (Table 1), which led to an increase in the average ratio $\left[\mathrm{O}_{2}\right] /[\mathrm{O}]$, as in summer.

As a rule, during geomagnetic disturbances $\left[\mathrm{O}_{2}\right] /[\mathrm{O}]$ values exceed those for quiet conditions: in spring and summer throughout the period the increase runs to 20 $\%$; in winter and fall, to $25 \%$. In summer seasons, $\left[\mathrm{O}_{2}\right] /[\mathrm{O}]$ is greater than that in winter for the entire period of interest: under quiet and disturbed conditions, by an average of $45-55 \%$.

\section{THE $[0] /\left[\mathrm{N}_{2}\right]$ RATIO}

Seasonal variations in $[\mathrm{O}] /\left[\mathrm{N}_{2}\right]$ under quiet geomagnetic conditions in 2014-2017 are displayed in Figure 2. The winter branch contains the largest values of $[\mathrm{O}] /\left[\mathrm{N}_{2}\right]$; the summer one, the lowest values. In 2015, noteworthy is a winter increase by $18 \%$, as compared to 2014 .

It is characteristic that in 2017 the average values of $[\mathrm{O}] /\left[\mathrm{N}_{2}\right]$ in all seasons decreased relative to those of 2014, by an average of $15 \%$ on both quiet and disturbed days.

As shown in [Shchepkin et al., 2009; Kushnarenko et al., 2011, 2014], during geomagnetic disturbances [O]/[ $\left.\mathrm{N}_{2}\right]$ at F1-layer heights almost always decreases, and the decrease depends on season and disturbance intensity. Note the greatest variations occurring during disturbances: in the winter of 2015 up to $30 \%$; in the fall of 2016 and in 2017 up to $25 \%$ and $35 \%$ respectively. In other seasons during the years, variations from quiet to disturbed conditions are within $10 \%$.

Winter values of $[\mathrm{O}] /\left[\mathrm{N}_{2}\right]$ exceed summer ones during quiet and disturbed periods in all the years considered by

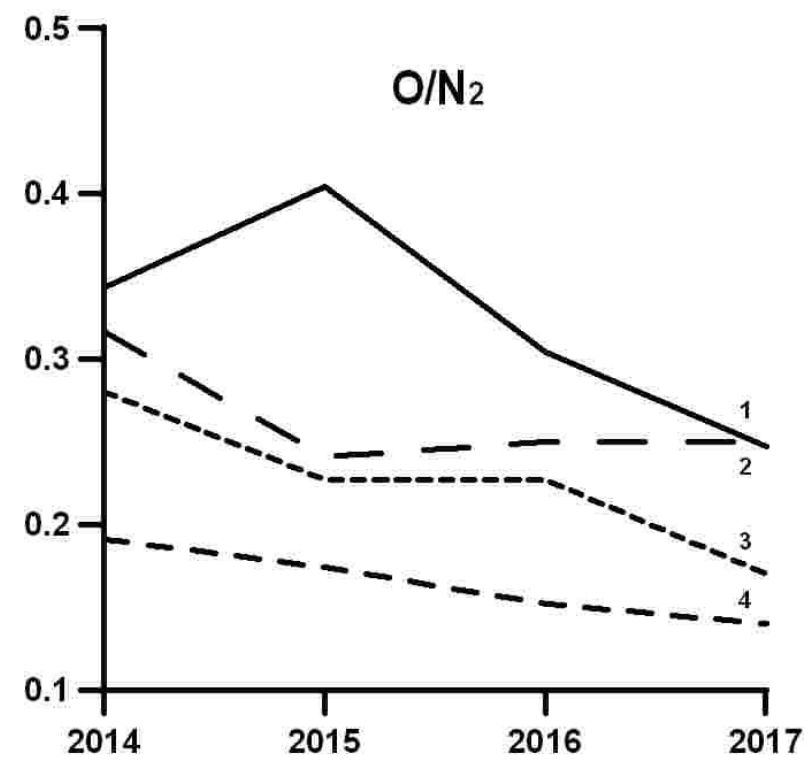

Figure 2. Seasonal variations in $[\mathrm{O}] /\left[\mathrm{N}_{2}\right]$ under quiet geomagnetic conditions: 1 - winter, 2 - fall, 3 - spring, 4 summer. Along the $\mathrm{X}$-axis are years of the period under study an average of 70-100\%, the largest deviations observed in 2015 .

Satellite measurements [Goncharenko et al., 2006] show that the gas composition in a disturbed zone is characterized by a decrease in the atomic oxygen concentration and a substantial increase in the molecular nitrogen concentration. These variations occur not only in summer during solar minimum, but also over the entire solar cycle during disturbed periods [Lastovicka, $2002]$, as also confirmed by our estimates of $[\mathrm{O}] /\left[\mathrm{N}_{2}\right]$ and $\left[\mathrm{O}_{2}\right] /[\mathrm{O}]$ in the years considered.

\section{COMPARISON OF ESTIMATED $[\mathrm{O}] /\left[\mathrm{N}_{2}\right]$ AND $\left[\mathrm{O}_{2}\right] /[\mathrm{O}]$ WITH MODEL VALUES}

Kushnarenko et al. [2011] have compared calculated $[\mathrm{O}] /\left[\mathrm{N}_{2}\right]$ and $\left[\mathrm{O}_{2}\right] /[\mathrm{O}]$ with the corresponding values obtained from MSIS for the period of solar activity decay (2003-2005). The conditions we study (see Table 1) are comparable with the conditions that existed in 2003-2005. This enables us to compare, as an example, our estimates of $[\mathrm{O}] /\left[\mathrm{N}_{2}\right]$ and $\left[\mathrm{O}_{2}\right] /[\mathrm{O}]$ with model values for May 2005 (see Table 3 in [Kushnarenko et al., 2011]) when three severe geomagnetic disturbances occurred: on May 8 (Dst $=-127$ $\mathrm{nT})$, May 15 (Dst=-263 nT), and May 30 (Dst=-138 $\mathrm{nT})$. The ratios $r_{1}=[\mathrm{O}] /\left[\mathrm{N}_{2}\right] /[\mathrm{O}] /\left[\mathrm{N}_{2}\right]_{\mathrm{MSIS}}$ and $r_{3}=\left[\mathrm{O}_{2}\right] /[\mathrm{O}] /\left[\mathrm{O}_{2}\right] /[\mathrm{O}]_{\mathrm{MSIS}}$ show that $[\mathrm{O}] /\left[\mathrm{N}_{2}\right]$ and $\left[\mathrm{O}_{2}\right] /[\mathrm{O}]$ we calculated change during both disturbed and quiet days, as compared to the corresponding MSIS values.

Under quiet conditions, the differences of our estimates from the model ones are of the order of 10 to 15 $\%$; during major disturbances the $[\mathrm{O}] /\left[\mathrm{N}_{2}\right]$ values exceed those obtained by the MSIS model by $8-18 \%$. The difference between $\left[\mathrm{O}_{2}\right] /[\mathrm{O}]$ and the model ones ranges from 5 to $20 \%$.

Comparison between $\left[\mathrm{O}_{2}\right] /[\mathrm{O}]$ and $[\mathrm{O}] /\left[\mathrm{N}_{2}\right]$ for other seasons of another year (2003) of the period of solar activity decay also shows a significant difference from model values during severe and moderate geomagnetic disturbances. This leads to the following conclusions.

1. For periods of severe geomagnetic disturbances in October and November 2003, our estimates of $[\mathrm{O}] /\left[\mathrm{N}_{2}\right]$ and $\left[\mathrm{O}_{2}\right] /[\mathrm{O}]$ were half as high as model values, in May and September the decrease reached $30 \%$.

2. For periods of moderate and weak disturbances, our estimates of $[\mathrm{O}] /\left[\mathrm{N}_{2}\right]$ are lower than the corresponding model values by $10-20 \%$ and lower than values for quiet days by $25-35 \%$. The ratio $\left[\mathrm{O}_{2}\right] /[\mathrm{O}]$ exceeds the model values by $20-50 \%$ and are $1.5-2$ times higher than the values for quiet days.

\section{CONCLUSION}

1. We have found that in summer under quiet geomagnetic conditions the relative content of molecular oxygen $\left[\mathrm{O}_{2}\right] /[\mathrm{O}]$ increases as solar activity decreases.

2. At heights below $200 \mathrm{~km}$ during geomagnetic disturbances, the relative molecular content of the neu- 
tral thermospheric component increases and that of the atomic one decreases. During disturbances, averages of $\left[\mathrm{O}_{2}\right] /[\mathrm{O}]$ exceed those for quiet conditions in all seasons of 2014-2017 and may run to $20 \%$ in spring and summer and to $25 \%$ in winter and fall. $[\mathrm{O}] /\left[\mathrm{N}_{2}\right]$ during disturbances decreases in winter and fall in some years by 25-35\%; in summer and spring, within $10 \%$.

3. With respect to the initial values of $2014,\left[\mathrm{O}_{2}\right] /[\mathrm{O}]$ increases by 2017 under both quiet and disturbed geomagnetic conditions: in summer and spring up to $30 \%$ and $20 \%$ respectively; in winter and fall, to $10 \%$. At the same time, $[\mathrm{O}] /\left[\mathrm{N}_{2}\right]$ decreases by 2017 as compared to 2014 during quiet and disturbed days by an average of $15 \%$.

4. The estimates of the main thermospheric gas components made in our previous works have revealed a considerable disagreement with the corresponding values obtained by the MSIS model during severe and moderate geomagnetic disturbances during solar activity decay. Since we have used experimental material on the electron density and SEM coefficients obtained on its basis for Irkutsk, we can assume that under disturbed conditions the real gas composition differs significantly from the model one. The estimates of the main gas components made using the currently available technique allow us to correct the thermospheric model for specific heliogeophysical conditions. It is important that this problem can be solved using regular ionospheric measurements by a method of vertical sounding.

The work was performed with budgetary funding of Basic Research program II.16 (Project II.16.1.1 «Research into the influence of solar activity and processes in the lower atmosphere on thermodynamic characteristics of the atmosphere, World Ocean, and climate»). The results were obtained using the equipment of Center for Common Use «Angara» [http://ckp-rf.ru/ckp/3056].

\section{REFERENCES}

Goncharenko L., Salah J., Crowley G., Paxton L.J., Zhang Y., Coster A., Rideout W., Huang C., Zhang S., Reinisch B., Taran V. Large variations in the thermosphere and ionosphere during minor geomagnetic disturbances in April 2002 and their association with IMF $B_{\mathrm{y}}$. J. Geophys. Res. 2006, vol. 111, A03303. DOI: 10.1029/2004JA010683.

Hedin A.E. MSIS-86 thermospheric model. J. Geophys. Res. 1987, vol. 92, no. A5, pp. 4649-4662.

Kushnarenko G.P., Kuznetsova G.M., Kolpakova O.E. The estimations of the ratios of the major gas constituents during strong and moderate geomagnetic disturbances in the descending phase of solar activity and solar minimum. Solnechno-zemnaya fizika [Solar-Terrestrial Physics]. 2011, vol. 19, pp. 134-139. (In Russian).

Kushnarenko G.P., Kuznetsova G.M., Yakovleva O.E Seasonal changes of the thermospheric main gas components ratios during the last solar activity minimum (2007-2009). Solnechno-zemnaya fizika [Solar-Terrestrial Physics]. 2014, vol. 25, pp. 29-32. (In Russian).

Kushnarenko G.P., Yakovleva O.E., Kuznetsova G.M. Long-term variations in neutral gas composition of the thermosphere above Irkutsk. Solnechno-zemnaya fizika [SolarTerrestrial Physics]. 2015, vol. 1, no. 4, pp. 30-34. DOI: 10.12737/13457. (In Russian).

Lastovicka J. Monitoring and forecasting of ionospheric space weather-effects of geomagnetic storms. J. Atmos. SolarTerr. Phys. 2002, vol. 64, pp. 697-705.
Picone J.M., Hedin A.E., Drob D.P., Aikin A.C. (GTD72000) NRLMSISE-00 Empirical model of the atmosphere: statistical comparisons and scientific issues. J. Geophys. Res. 2002, vol. 107, no. A12, p. 1469. DOI: 10.1029/2002JA009430.

Tobiska W.K., Eparvier F.G. EUV97: Improvements to EUV irradiance modeling in the soft X-rays and EUV. Solar Phys. 1998, vol. 147, no. 1, pp. 147-159.

Shchepkin L.A., Kushnarenko G.P., Kuznetsova G.M., Freizon I.A. The middle ionosphere parameters dependence upon the solar and geomagnetic activities. 1. The development degree of the F1 layer. Geomagnetizm $i$ aeronomiya [Geomagnetism and Aeronomy]. 1998, vol. 38, no. 5, pp. 72-76. (In Russian).

Shchepkin L.A., Kushnarenko G.P., Kuznetsova G.M. The possibility of estimations of the atomic and molecular oxygen relative abundance according to electron density measurements in the middle ionosphere. Geomagnetizm $i$ aeronomiya [Geomagnetism and Aeronomy]. 2008, vol. 48, no. 1, pp. 129-133. (In Russian).

Shchepkin L.A., Kuznetsova G.M., Kushnarenko G.P. The estimations of atomic and molecular oxygen the relative abundance at height of $120 \mathrm{~km}$ according to the ionospheric measurements. Geomagnetizm i aeronomiya [Geomagnetism and Aeronomy]. 2009, vol. 49, no. 4, pp. 350-353. (In Russian). 2020).

URL: http://ckp-rf.ru/ckp/3056 (accessed January 31, 2020).

URL: http://wdc.kugi.kyoto-u.ac.jp (accessed January 31,

How to cite this article

Kushnarenko G.P., Yakovleva O.E., Kuznetsova G.M. Estimated relations between the main thermospheric neutral components at ionospheric F1-layer heights above Irkutsk in 2014-2017. Solar-Terrestrial Physics. 2020. Vol. 6. Iss. 3. P. 90-93. DOI: 10.12737/stp-63202013. 